there is duplication between related papers, but there are few errors or infelicities to mar the perfection of the volume.

Dava Sobel's Longitude was inspired by the same symposium, but it is as different as could be: it is a small book, by one author, without illustrations and almost without any numbers (except dates). This is the same story of Harrison's lifelong struggle with the mechanisms and the Board of Longitude, set out in a more dramatic fashion. The astronomers on the board were keen to see the money going towards better tables of lunar motion, and their bias against Harrison led to malpractices scandalous enough to make a good story.

The book is well written in American idiom and deserves its bestseller status. Longitude is usually regarded as boring, but here the action moves forward like a novel. A talking-book version is already on sale; an illustrated version is presumably on the way; and why not a television series or film? Before the hype gets out of hand, I should mention that there are some errors. The worst is in the sentence in parentheses on page 36: any sailors who calculate their longitude by this method risk being shipwrecked ("minutes and seconds" at the end should be "degrees and minutes").

Both books serve science well, and show its human face. The success of Longitude suggests that other stories of events in science, technology or medicine might be retold just as memorably.

Desmond King-Hele worked as a space scientist for 40 years and is now writing a biography of Erasmus Darwin.

\section{Backcloth of mystery}

\section{Relic, Icon or Hoax? Carbon Dating} the Turin Shroud

by H. E. Gove

Institute of Physics Publishing: 1996. Pp. 336. $\mathfrak{E} 19.50, \$ 35$

\section{Robert Hedges}

The origin of the Turin Shroud, with its unexplained image, is still the subject of doubts and questions. What is not doubted is the remarkable fascination the shroud holds for so many people. This unusual book attests the power of that fascination for the author, a physicist who played a principal role in developing the technique by which the shroud textile was eventually dated; and I dare say it will enthral those readers gripped by the minutiae of how the dating took place.

People of Christian faith may reasonably be expected to regard Christ's burial shroud as a supremely important object. But sanctifying the shroud not only cuts it off from the world, it makes the sacred susceptible to scientific validation. In fact, the Roman Catholic Church has avoided offering such a hostage to fortune. Nevertheless, the pressure to sanctify relics is great; perhaps it recalls a distant time when all around us was regarded as holy. For others, the fascination appears more profane; they seem unable to leave open such questions as how the image was produced. Finally, there is a large measure of self-amplifying hype.

Against this heady backcloth of public interest, H. E. Gove had a key part in arranging the radiocarbon dating of the shroud. He seems to have kept extensive notes, and this book is a blow by blow, or rather telephone call by telephone call, account of his participation in the drama. It is largely autobiographical, while providing a journalistic, gossipy sort of history.

One feels that writing the book helped Gove to come to terms with his personal frustration about the way events unfolded. To have been foremost in developing the new dating technique, and to have been a prime agent for putting the Turin Shroud to the test, and then at a late stage to find that one's laboratory had been disinvited, was evidently deeply galling. It must explain some bitter personal remarks in this otherwise reasonably objective account.

The fascination of the shroud did indeed engender a level of competitive energy and hypocrisy rare in pure science. Both the account of the relationship between the radiocarbon-dating consortium and members of the Shroud of Turin Research Project, and the story of how the original selection of seven radiocarbon laboratories was reduced to three, provide interesting reading about some all-too-human aspects of scientific work. Gove writes that the elimination of his laboratory's participation was "inexplicable". This seems naivethe laboratories chosen were the ones with the greatest experience of archaeological dating, and all subsequent questioning of the date has been in terms of archaeological dating (validity and context of sample and questions of contamination).

Gove writes, more than once, that the technique was invented at his laboratory at the University of Rochester, New York. It seems poor judgement not to mention Nelson's work at McMaster University in Hamilton, Ontario, until an appendix (which credits Nelson with making the first carbon-14 measurements "virtually simultaneously" with Gove and his co-workers). But on factual events, I could find nothing I knew personally to be wrong, and am happy to accept the rest as accurate.

I am not sure at whom the book is aimed. Shroud aficionados will no doubt revel in the loving detail. But those wanting to understand the various issues - the state of evidence before the dating, the position of the ecclesiastical authorities, the scientific basis of radiocarbon dating - may feel dissatisfied. The writing is lean and athletic, making it easy to enjoy reading the most trivial detail, and I found the pen sketches of my colleagues good fun. Even so, the relentless details of memoranda, meetings and telephone calls had stifled my interest long before I reached the account of the result of the dating. Gove covers the postresult period more briefly, perhaps because he was far less involved, although he does deal with most of the obstacles to accepting the date that were subsequently raised.

To convince the doubters, a much fuller and more energetic treatment is called for, and I feel this is a missed opportunity. The whole issue of the conflict in those whologically accept the scientific results and yet whose faith decrees those results to be in error has its own fascination, and deserves thoughtful and sympathetic treatment. But this is not that kind of book.

Robert Hedges is at the Research Laboratory for Archaeology, University of Oxford, 6 Keble Road, Oxford OX1 3QJ, UK.

\section{The short-range forces of nature}

\section{The Quantum Theory of Fields. Volume 2: Modern Applications}

by Steven Weinberg

Cambridge University Press: 1996. Pp. 489.

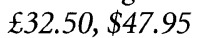

\section{John C. Taylor}

Quantum field theory arose around 1930 as the rather inevitable result of combining quantum theory with special relativity. By 1950 , quantum electrodynamics had been tamed, and the Lamb shift and the anomalous magnetic moment of the electron accurately calculated. These things and more were covered in volume 1 of Steven Weinberg's book, reviewed in Nature by S. S. Schweber $(377,396 ; 1995)$.

People naturally tried to apply quantum field theory to the other forces between subnuclear particles: the strong and the weak forces. These forces, in contrast to the electromagnetic ones, are of short range. At first there was not much success, and some physicists even doubted whether quantum field theory was the right framework in which to think about these nuclear forces. The breakthrough came towards the end of the 1960s when it was understood how to handle spin-one particles which differed from the photon in having mass and charge. These are the particles that are now known to mediate the short-range forces.

The problems were, first, how to avoid getting negative probabilities as a consequence of the minus sign in the Lorentz 